\title{
Hovenia dulcis Thunb. pseudofruits as functional foods: Phytochemicals and bioactive properties in different maturity stages
}

\author{
Patricia Morales ${ }^{\mathrm{a}, \mathrm{b}, *}$, Helayne Aparecida Maieves ${ }^{\mathrm{a}, \mathrm{c}}$, Maria Inês Dias ${ }^{\mathrm{b}, \mathrm{d}}$, Ricardo C. Calhella ${ }^{\mathrm{b}}$, \\ María Cortes Sánchez-Mata ${ }^{a}$, Celestino Santos-Buelga ${ }^{\mathrm{e}}$, Lillian Barros ${ }^{\mathrm{b}, \mathrm{d}}$, Isabel C.F.R. Ferreira ${ }^{\mathrm{b}, *}$ \\ a Dpto. Nutrición y Bromatología II, Facultad de Farmacia, Universidad Complutense de Madrid (UCM), Plaza Ramón y Cajal, s/n, 28040 Madrid, Spain \\ ${ }^{\mathrm{b}}$ Mountain Research Centre (CIMO), ESA, Polytechnic Institute of Bragança, Campus de Santa Apolónia, 1172, 5300-253 Bragança, Portugal \\ ${ }^{c}$ Faculdade de Nutrição-Gastronomia, Universidade Federal de Pelotas, Av. Gomes Carneiro, 01 Campus Anglo, Porto, 96010-610 Pelotas, RS, Brazil \\ ${ }^{\mathrm{d}}$ Laboratory of Separation and Reaction Engineering, Laboratory of Catalysis and Materials (LSRE-LCM), Polytechnic Institute of Bragança, Campus de Santa Apolónia, 1134, \\ 5301-857 Bragança, Portugal \\ ${ }^{\mathrm{e}}$ Grupo de Investigación en Polifenoles (GIP-USAL), Facultad de Farmacia, Universidad de Salamanca, Campus Miguel de Unamuno, 37007 Salamanca, Spain
}

\section{A R T I C L E I N F O}

\section{Article history:}

Received 13 July 2016

Received in revised form 23 November 2016

Accepted 2 December 2016

Available online 18 December 2016

\section{Keywords:}

Hovenia dulcis Thunb.

Pseudofruits

Phytochemicals

Antioxidant/antitumor/antimicrobial

capacity

Ripening process

\begin{abstract}
A B S T R A C T
Pseudofruits of Hovenia dulcis, at five different ripening stages, were evaluated in order to characterize their bioactive compounds (phenolic compounds, tocopherols and fatty acids), and determine their biofunctionality (antitumor, antimicrobial and antioxidant activity). Epi(gallochatechin) was the main phenolic compound $(24.7 \mathrm{mg} / \mathrm{g}$, Hd05), $\alpha$-tocopherol was the main isoform, increasing its content with the maturity process $(5.43 \mathrm{mg} / 100 \mathrm{~g}$, Hd04), C18:2 was the main polyunsaturated fatty acid (35.5\%, Hd04), while C16:0 was the predominant saturated fatty acids (38\%, Hd01). The most immature stages (Hd01-Hd02) showed antitumor activity against all tested tumor cell lines, mainly against NCI-H460; also Hd01 and Hd02 presented the highest antimicrobial activity, mainly against Pseudomonas aeruginosa and Staphylococcus aureus. This underutilized product demonstrated to be a rich source of phenolic compounds and tocopherols showing an interesting activity in immature stages (unfit for consumption in natura) and could be use as alternative bioactive ingredient for functional foods, dietary supplements or nutraceuticals.
\end{abstract}

(c) 2016 Elsevier Ltd. All rights reserved.

\section{Introduction}

Pseudofruits are stems from a single flower that, as a result of fertilisation, have the development of an organ in addition to the accessory ovary (Chitarra \& Chitarra, 2005). In the case of Hovenia dulcis Thunb., traditionally known as rasing tree, the mature peduncle, that is the edible part, was commonly and erroneously called fruit (Fig. 1). Tasty pulp of ripe pear aroma reminiscent of peduncle presents a good acceptance for human consumption due to the high levels of sugars, especially sucrose (Carvalho, 1994; Maieves, Ribani, Morales, \& Sánchez-Mata, 2015a).

Hovenia dulcis pseudofruit, whose popular name is Japanese grape, has a long history as a food supplement and traditional med-

\footnotetext{
* Corresponding authors at: Dpto. Nutrición y Bromatología II, Facultad de Farmacia, Universidad Complutense de Madrid (UCM), Plaza Ramón y Cajal, s/n, 28040 Madrid, Spain (P. Morales), Mountain Research Centre (CIMO), ESA, Polytechnic Institute of Bragança, Campus de Santa Apolónia, 1172, 5300-253 Bragança, Portugal (I.C.F.R. Ferreira).

E-mail addresses: patricia.morales@farm.ucm.es (P. Morales), iferreira@ipb.pt (I.C.F.R. Ferreira).
}

icine in Japan, China and Korea, but it is quite unknown and scarcely used in Western countries (Hyun, Eom, Yu, \& Roitsch, 2010; Rigatto, Pereira, Mattos, \& Schaitza, 2001). It is cultivated in China, invasive in South American rainforests, being widely distributed in Brazil, and Tanzania, and has been introduced as a rare ornamental in different countries including the USA, Australia, New Zealand and Central Africa (Hung et al., 2010). According to Hyun et al. (2010), in East Asia, H. dulcis has long been used in traditional herbal medicine, being traditionally employed in the treatment of liver diseases and detoxification after alcoholic poisoning; also, in ancient Chinese medicine, its fruits and peduncles have been used as a febrifuge and administered to treat parasitic infections, as antispasmodic, laxative and diuretic agent. Seeds have been used as a diuretic being also useful in alcohol intoxication.

Previous studies have revealed further pharmaceutical applications of $H$. dulcis based on its anti-inflammatory effects (inhibition of KappaB-alpha phorylation and nuclear translocation of nuclear factor-KappaB), hepatoprotective effect (preventive effect on D-GalN/LPS-induced liver injury) and alcohol detoxification effect, among others (Hase et al., 1997; Ji, Yang, \& Li, 2000). In this way, 


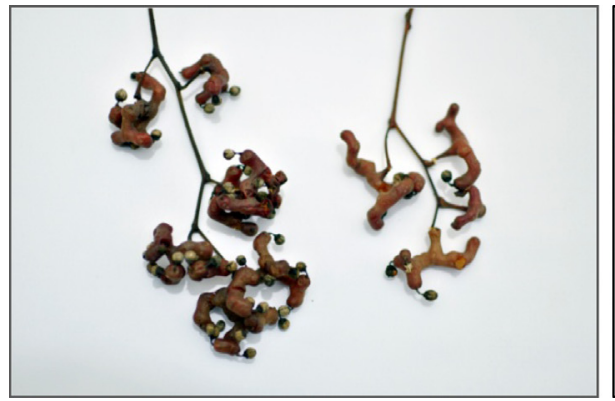

Hd01

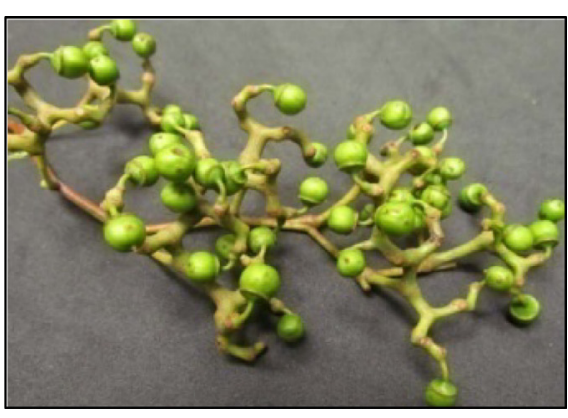

Hd05

Fig. 1. Hovenia dulcis Thunb. pseudofruits: immature stage and the optimum stage for food consumption (Hd01 and Hd05, respectively).

different studies have demonstrated that polysaccharides from the peduncles of $H$. dulcis have a significant hepatoprotective effect on acute alcohol-induced liver injury in mice via its antioxidant capacity. Its phenolic compounds have been shown to induce protective effects on glutamate-induced neurotoxicity in HT22 cells, which was related with free radical scavenging activities (Cha, Lee, Lee, \& Park, 2004; Kiyoshi, 1987).

The nutritional profile and rheological properties of this pseudofruit have been previously studied (Maieves et al., 2015a, 2015b, 2016). Furthermore, the types of phenolic compounds (in terms of total contents) in $\mathrm{H}$. dulcis peduncles have been already investigated (Maieves et al., 2015b). However, the information about the individual phenolic compounds in what concerns to the effects of maturation process is scarce. Therefore, the main objective of this work was to analyse the pseudofruits of $H$. dulcis in different stages of maturation, in order to characterize some bioactives such as phenolic compounds, tocopherols and fatty acids, as well as to determine its biofunctionality in terms of antitumor activity in different human tumor cell lines, antimicrobial properties, and antioxidant capacity.

\section{Material and methods}

\subsection{Standards and reagents}

Methanol was of analytical grade purity and supplied by Pronalab (Lisbon, Portugal). HPLC-grade acetonitrile, n-hexane and ethyl acetate were obtained from Merck KgaA (Darmstadt, Germany) and Lab-Scan (Lisbon, Portugal), respectively. Formic and acetic acids were purchased from Prolabo (VWR International, Fontenay-sous-Bois, France). The fatty acids methyl ester (FAME) reference standard mixture 37 (standard $47885-U$ ) as well as other individual fatty acid isomers, tocopherol standards $(\alpha, \beta, \gamma$ and $\delta$ isoforms), glucose, fructose, sucrose, organic acid standards (L (+)-ascorbic, oxalic, malic, citric and quinic acids), acetic acid, formic acid, ellipticine, sulphorhodamine B (SRB), trypan blue, trichloroacetic acid (TCA), 2,3,5-triphenyltetrazolium chloride (TTC) and chloramphenicol were purchased from Sigma (St. Louis, MO, USA). Phenolic compound standards (catechin, naringenin, quercetin-3-O-rutinoside, quercetin-3-O-glucoside, taxifolin, isorhamentin-3-O-rutinoside) were from Extrasynthese (Genay, France). Racemic tocol in n-hexane, $50 \mathrm{mg} / \mathrm{mL}$, was purchased from Matreya (Plesant Gap, PA, USA). The 2,2-diphenyl-1picrylhydrazyl (DPPH) used for the antioxidant capacity evaluation was obtained from Alfa Aesar (Ward Hill, MA, USA). Fetal bovine serum (FBS) L-glutamine, Hank's balanced salt solution (HBSS), trypsin-EDTA (ethylenediaminetetraacetic acid), penicillin/streptomycin solution ( $100 \mathrm{U} / \mathrm{mL}$ and $100 \mathrm{mg} / \mathrm{mL}$, respectively)), RPMI1640 and DMEM media were from Hyclone (Logan, Utah, USA). Water was treated in a Milli-Q water purification system (TGI Pure
Water Systems, Greenville, SC, USA). Mueller Hinton Broth from Difco (New Jersey, NY, USA).

\subsection{Plant material and sample preparation}

The pseudofruits of Hovenia dulcis Thunb. were collected for five consecutive months, in trees situated in the neighbourhood of Jardim das Américas, Curitiba-PR-Brazil, under the coordinates (S) $25^{\circ}$ 2056 and (W) 49 13 57. The most immature peduncles (Hd01) were collected in February, corresponding to a maturity degree (MD) of 0.52 (calculated as \% soluble sugars/titratable acidity expressed as \% tartaric acid). Then peduncles were collected approximately each month ( $\mathrm{Hd} 02, \mathrm{MD}=0.64 ; \mathrm{Hd} 03, \mathrm{MD}=4.61$; Hd04, MD = 9.17; Hd05, MD = 8.31). It should be noted that MD was used to better characterize the stage of each sample, however, it may not have the habitual significance, since this product is not a fruit, and thus its metabolism is expected to be different from real fruits. Stages Hd01 is the post-anthesis development, not suitable for food consumption (the most immature fruit), along with the stages HdO2 and Hd03. The full maturation phase with onset of senescence, corresponds to the stages Hd04 and Hd05 (the most mature fruit), which are suitable for fresh consumption.

Each sample was constituted by about $800-1000 \mathrm{~g}$ of peduncles, collected from at least two different trees, and a composite sample for each stage was prepared by mixing all the pseudofruits harvested. They were washed in water and left for 10 min under concentration of $200 \mathrm{ppm}$ sodium hypochlorite, then rinsed and freeze-dried (L101-Liotop, Brazil-São Carlos-SP). Finally the samples were stored at $-20^{\circ} \mathrm{C}$ until analysed. Determinations were performed in freeze-dried samples.

The hydromethanolic extraction was performed using the dry plant material $(1 \mathrm{~g})$ stirring with $30 \mathrm{~mL}$ of methanol:water $(80: 20, v / v)$ at $25^{\circ} \mathrm{C}$ and $150 \mathrm{rpm}$ for $1 \mathrm{~h}$, and filtered through Whatman No. 4 paper. The residue was then extracted with one additional $30 \mathrm{~mL}$ portion of the hydroalcoholic mixture. The combined extracts were evaporated at $35^{\circ} \mathrm{C}$ under reduced pressure (rotary evaporator Büchi R-210, Flawil, Switzerland) and then further lyophilized (FreeZone 4.5, Labconco, Kansas, USA) for further use in the phenolic compounds identification and to evaluate the bioactive properties (antioxidant, antitumor and antimicrobial assays).

\subsection{Bioactive compounds}

\subsubsection{Phenolic compounds}

Prior to the analysis, the extracts were dissolved in methanol/ water $80: 20 \mathrm{v} / \mathrm{v}(5 \mathrm{mg} / \mathrm{mL})$, filtered through a $0.22 \mu \mathrm{m}$ Whatman syringe filter and transferred to amber color vials. RP-HPLC analysis was performed to identified the phenolic compounds by using an Agilent 1100 series (Hewlett-Packard 1100, Agilent Technolo- 
gies, Santa Clara, CA, USA) as described by Barros et al. (2013). Double online detection was carried out in a PDA using $280 \mathrm{~nm}$ and $370 \mathrm{~nm}$ as preferred wavelengths, as well as a mass spectrometer API 3200 Qtrap (Applied Biosystems, Darmstadt, Germany) equipped with an ESI source and a triple quadrupole-ion trap mass analyzer that was controlled by the Analyst 5.1 software. Phenolic compounds were separated using a Spherisorb S3 ODS-2 $\mathrm{C}_{18}$ column ( $3 \mu \mathrm{m}, 4.6 \times 150 \mathrm{~mm}$, Waters, Milford, MA, EUA) at $35^{\circ} \mathrm{C}$, with $0.1 \%$ formic acid in water $(A)$ and acetonitrile (B), following the elution gradient: $15 \%$ B ( $5 \mathrm{~min}$ ), $15 \%$ B to $20 \%$ B (5 min), $20-25 \%$ B (10 $\mathrm{min}), 25-35 \%$ B (10 $\mathrm{min}), 35-50 \%$ B (10 min), and re-equilibration of the column (50-15\% B, $15 \mathrm{~min})$, using a flow rate of $0.5 \mathrm{~mL} / \mathrm{min}$. Phenolic compounds were identified by comparison with standard compounds, when available, or tentatively identified using reported information from literature. Quantification was based on calibration curves of available standards, using the peak area recorded at 280 and $370 \mathrm{~nm}$, when commercial standards were not available, quantification was performed using phenolic compounds from the same group. Results were expressed as mg per $g$ of extract.

\subsubsection{Fatty acids}

Fat was obtained after Soxhlet extraction and fatty acids were determined after the following methylation procedure: fatty acids were methylated with $5 \mathrm{~mL}$ of methanol:sulphuric acid:toluene 2:1:1 (v:v:v), in a bath at $50{ }^{\circ} \mathrm{C}, 160 \mathrm{rpm}$ over night; then $3 \mathrm{~mL}$ of deionised water was added to obtain phase separation; the FAME were recovered with $3 \mathrm{~mL}$ of diethyl ether by shaking in a vortex, and the upper phase was transferred to a vial with Teflon containing sodium sulphate anhydrous, in order to eliminate the water and before injection the sample was filtered with $0.22 \mu \mathrm{m}$ nylon filter from Milipore as described by the authors (Morales, Barros, Ramírez-Moreno, Santos-Buelga, \& Ferreira, 2015). Fatty acids characterization were determined by gas-liquid chromatography with flame ionization detection (GC-FID) with a DANI model GC 1000 instrument (Milan, Italy) equipped with a split/splitless injector, a flame ionization detector (FID at $260{ }^{\circ} \mathrm{C}$ ) and a MachereyNagel (Duren, Germany) column (30 $\mathrm{m} \times 0.32 \mathrm{~mm}$ i.d., $0.25 \mu \mathrm{m}$, $50 \%$ cyanopropyl-methyl-50\% phenylmethylpolysiloxane). The oven temperature program was as follows: the initial temperature of the column was $50^{\circ} \mathrm{C}$, held for $2 \mathrm{~min}$, then a $30^{\circ} \mathrm{C} / \mathrm{min}$ ramp to $125^{\circ} \mathrm{C}, 5^{\circ} \mathrm{C} / \mathrm{min}$ ramp to $160^{\circ} \mathrm{C}, 20^{\circ} \mathrm{C} / \mathrm{min}$ ramp to $180^{\circ} \mathrm{C}$, $3{ }^{\circ} \mathrm{C} / \mathrm{min}$ ramp to $200^{\circ} \mathrm{C}, 20^{\circ} \mathrm{C} / \mathrm{min}$ ramp to $220^{\circ} \mathrm{C}$ and held for $15 \mathrm{~min}$. The carrier gas (hydrogen) flow-rate was $4.0 \mathrm{~mL} / \mathrm{min}$ (0.61 bar), measured at $50{ }^{\circ} \mathrm{C}$. Split injection (1:40) was carried out at $250^{\circ} \mathrm{C}$. Fatty acid identification was made by comparing the relative retention times of FAME peaks from samples with standards. The results were recorded and processed using Clarity Software (DataApex, Prague, The Czech Republic) and expressed in relative percentage of each fatty acid.

\subsubsection{Tocopherols}

Tocopherols were determined by HPLC-FL, using a fluorescence detector (FP-2020; Jasco; Easton, MD, USA) programmed for excitation at $290 \mathrm{~nm}$ and emission at $330 \mathrm{~nm}$, separation was performed with a Polyamide II $(250 \times 4.6 \mathrm{~mm})$ normal-phase column from YMC Waters operating at $30^{\circ} \mathrm{C}$. The mobile phase used was a mixture of n-hexane and ethyl acetate (70:30, v/v) at a flow rate of $1 \mathrm{~mL} / \mathrm{min}$. Extraction procedure was performed following the procedure described by the authors (Morales et al., 2015), BHT (butylhydroxytoluene) solution in hexane $(10 \mathrm{mg} / \mathrm{mL}$; $100 \mu \mathrm{L}$ ) and internal standard (IS) solution in hexane (tocol; $2.0 \mu \mathrm{g} / \mathrm{mL} ; 250 \mu \mathrm{L}$ ) were added to the sample (500 mg) prior to the extraction procedure. Samples were homogenised with methanol $(4 \mathrm{~mL})$ by vortex mixing (1 min). Subsequently, hexane $(4 \mathrm{~mL})$ was added and vortex mixed again for $1 \mathrm{~min}$. After that, saturated
$\mathrm{NaCl}$ aqueous solution ( $2 \mathrm{~mL}$ ) was added, the mixture was homogenised ( $1 \mathrm{~min}$ ), centrifuged (Centurion K24OR-2003 refrigerated centrifuge, $5 \mathrm{~min}, 6200 \mathrm{rpm}$ ) and the clear upper layer was carefully transferred to a vial containing anhydrous sodium sulphate. The residue was re-extracted twice with hexane. The combined extracts were evaporated to dryness under a nitrogen stream, redissolved in $2 \mathrm{~mL}$ of $\mathrm{n}$-hexane, filtered through a $0.22 \mu \mathrm{m}$ disposable LC filter disk, transferred into a dark injection vial and analysed by HPLC. The compounds were identified by chromatographic comparisons with authentic standards. Quantification was based on the fluorescence signal response of each standard, using the IS (tocol) method and by using calibration curves obtained from commercial standards of each compound. The results were expressed as mg per $100 \mathrm{~g}$ of dry weight.

\subsection{Bioactive properties}

The extracts were re-dissolved in methanol/water $80: 20 \mathrm{v} / \mathrm{v}$ (concentration of $10 \mathrm{mg} / \mathrm{mL}$ ) and water (concentration of $8 \mathrm{mg} / \mathrm{mL}$ ), for antioxidant and antitumor assays respectively, and stored at $4{ }^{\circ} \mathrm{C}$ ( 2 days) for further use. For antimicrobial assay the extracts were diluted in water, with an end concentration of $100 \mu \mathrm{g} / \mathrm{mL}$

\subsubsection{Antioxidant capacity assays}

2.4.1.1. DPPH radical-scavenging activity. DPPH radical-scavenging activity was performed using an ELX800 Microplate Reader (BioTek Instruments, Inc., Winooski, VT, USA) and calculated as a percentage of DPPH discolouration using the formula: [(ADPPH-AS)/ $\mathrm{ADPPH}] \times 100$, where AS is the absorbance of the solution containing the sample at $515 \mathrm{~nm}$, and ADPPH is the absorbance of the DPPH solution, according to Morales et al. (2015). The reaction mixture in each one of the 96-wells consisted of one of the different concentrations (range from 0.078 to $10 \mathrm{mg} / \mathrm{mL}$ of extract) of the extracts $(30 \mu \mathrm{L})$ and aqueous methanolic solution $(80: 20 \mathrm{v} / \mathrm{v}$, $270 \mu \mathrm{L})$ containing DPPH radicals $\left(6 \times 10^{-5} \mathrm{~mol} / \mathrm{L}\right)$, and left to stand for $60 \mathrm{~min}$ in the dark. The extract concentration providing $50 \%$ of radicals scavenging activity $\left(\mathrm{EC}_{50}\right)$ was calculated from the graph of radical-scavenging activity (RSA) percentage against extract concentration. Trolox was used as positive control.

2.4.1.2. Reducing power. Reducing power was evaluated by the capacity to convert $\mathrm{Fe}^{3+}$ into $\mathrm{Fe}^{2+}$, measuring the absorbance at $690 \mathrm{~nm}$ in the microplate reader mentioned above following the procedure described by Morales et al., 2015). Different concentrations of the extracts $(0.5 \mathrm{~mL})$ were mixed with sodium phosphate buffer $(200 \mathrm{mmol} / \mathrm{L}, \mathrm{pH} 6.6,0.5 \mathrm{~mL})$ and potassium ferricyanide $(1 \% \mathrm{w} / \mathrm{v}, 0.5 \mathrm{~mL})$. The mixture was incubated at $50{ }^{\circ} \mathrm{C}$ for $20 \mathrm{~min}$, and trichloroacetic acid $(10 \% \mathrm{w} / \mathrm{v}, 0.5 \mathrm{~mL})$ was added. The mixture $(0.8 \mathrm{~mL})$ was poured in the 48 -wells, as also deionised water $(0.8 \mathrm{~mL})$ and ferric chloride $(0.1 \% \mathrm{w} / \mathrm{v}, 0.16 \mathrm{~mL})$, and the absorbance was measured at $690 \mathrm{~nm}$ in the Microplate Reader described above. The extract concentration providing 0.5 of absorbance $\left(\mathrm{EC}_{0.5}: 50 \%\right.$ of the maximal absorbance) was calculated from the graph of absorbance at $690 \mathrm{~nm}$ against extract concentration. Trolox was used as positive control.

2.4.1.3. Inhibition of $\beta$-carotene bleaching inhibition. Inhibition of $\beta$-carotene bleaching was evaluated through the $\beta$-carotene/ linoleate assay; the neutralization of linoleate free radicals avoids $\beta$-carotene bleaching, which is measured at $470 \mathrm{~nm}$ and calculated by the formula: $\beta$-carotene absorbance after $2 \mathrm{~h}$ of assay/initial absorbance) $\times 100$. A solution of $\beta$-carotene was prepared by dissolving $\beta$-carotene $(2 \mathrm{mg})$ in chloroform $(10 \mathrm{~mL})$. Two millilitres of this solution were pipetted into a round-bottom flask. After the chloroform was removed at $40{ }^{\circ} \mathrm{C}$ under vacuum, linoleic acid 
(40 mg), Tween 80 emulsifier (400 mg), and distilled water $(100 \mathrm{~mL})$ were added to the flask with vigorous shaking. Aliquots $(4.8 \mathrm{~mL})$ of this emulsion were transferred into different test tubes containing different concentrations of the extracts $(0.2 \mathrm{~mL})$. The tubes were shaken and incubated at $50{ }^{\circ} \mathrm{C}$ in a water bath. As soon as the emulsion was added to each tube, the zero time absorbance was measured at $470 \mathrm{~nm}$. The extract concentration providing $50 \%$ antioxidant capacity $\left(\mathrm{EC}_{50}\right)$ was calculated by interpolation from the graph of $\beta$-carotene bleaching inhibition percentage against extract concentration. Trolox was used as positive control.

\subsubsection{Antitumor activity and hepatotoxicity}

Four human tumor cell lines were used: MCF7 (breast adenocarcinoma), HCT15 (colon carcinoma), HeLa (cervical carcinoma) and HepG2 (hepatocellular carcinoma). Cells were routinely maintained as adherent cell cultures in RPMI-1640 medium containing 10\% heat-inactivated FBS and $2 \mathrm{mM}$ glutamine (MCF7 and HCT15) or in DMEM supplemented with 10\% FBS, 2 mM glutamine, $100 \mathrm{U} /$ $\mathrm{mL}$ penicillin and $100 \mathrm{mg} / \mathrm{mL}$ streptomycin (HeLa and HepG2 cells), at $37{ }^{\circ} \mathrm{C}$, in a humidified air incubator containing $5 \% \mathrm{CO}_{2}$. Each cell line was plated at an appropriate density $\left(7.5 \times 10^{3}\right.$ cells/well for MCF7 and HCT15 or $1.0 \times 10^{4}$ cells/well for HeLa and HepG2) in 96-well plates. Sulphorhodamine B assay was performed according to a procedure described by the authors (Carocho et al., 2015). Ellipticine was used as positive control.

To check the possibility of damaging non-tumor liver cells, hepatotoxicity was evaluated using a cell culture (PLP2) prepared from a freshly harvested porcine liver obtained from a local slaughterhouse, according to an established procedure (Abreu et al., 2011). Cell culture was continued with direct monitoring every 2-3 days using a phase contrast microscope. Before confluence was reached, cells were sub-cultured and plated in 96-well plates at a density of $1.0 \times 10^{4}$ cells/well, and cultivated in DMEM medium with $10 \%$ FBS, $100 \mathrm{U} / \mathrm{mL}$ penicillin and $100 \mu \mathrm{g} / \mathrm{mL}$ streptomycin. Ellipticine was used as positive control. The results were expressed in $\mathrm{GI}_{50}$ values (sample concentration that inhibited $50 \%$ of the net cell growth).

\subsubsection{Antimicrobial activity}

The Minimum inhibitory concentration (MIC) was determined based on the methodology described in the document National Committee for Clinical Laboratory Standards (NCCLS - National Committee For Clinical Laboratory Standards, 1997) and consisted in distributing $160 \mu \mathrm{L}$ of Müller-Hinton Broth (MH) in each well of a dilution microplate with 96 wells, arranged in 12 columns (1-12) and 8 lines $(\mathrm{A}-\mathrm{H})$. Each one of these boards was the analysis of one at the following microorganism: Escherichia coli (25922), Enterococcus faecalis (29212), Pseudomonas aeruginosa (27853), Staphylococcus epidermidis (12228) and Staphylococcus aureus (25932). Serial dilutions of the sample extracts were processed and $100 \mu \mathrm{L}$ distributed into each hole of the microplate, sterile, of 96 wells. Then $5 \mu \mathrm{L}$ of bacterial inoculants containing $5 \times 10^{5} \mathrm{UFC} / \mathrm{mL}$ of each bacterium were added, and the plates were incubated in aerobic medium at $36{ }^{\circ} \mathrm{C} \pm 1{ }^{\circ} \mathrm{C}$ for $24 \mathrm{~h}$. After that, $10 \mu \mathrm{L}$ of $5 \%(v: v)$ 2,3,5-triphenyltetrazolium chloride solution (TTC) in methanol were added, to each well of the microplates used, which were taken for incubation in aerobic conditions during $30 \mathrm{~min}$ at $36^{\circ} \mathrm{C} \pm 1^{\circ} \mathrm{C}$, to check for bacterial growth. Over the course of $2 \mathrm{~h}$ the wells which showed activity remain colourless after adding TTC (an oxidation-reduction indicator used to differentiate metabolically active tissues of those not active, mainly cell viability), while the wells in which there was microbial growth blush of red (Duarte, Figueira, Sartoratto, Rehder, \& Delarmelina, 2005; Gabrielson et al., 2002). Chloramphenicol was used, at $30 \mu \mathrm{g} / \mathrm{mL}$, as standard antimicrobial. The determination of MIC, was defined as the lowest concentration of the extract, able to prevent micro- bial growth, that is, on presence or absence of turbidity, being agreed the presence of turbidity and bacterial growth and absence as no bacterial growth. Thus, it was considered the lowest concentration $(\mu \mathrm{g} / \mathrm{mL}$ extract) of the extract that can provide a complete inhibition of growth.

\subsection{Statistical analysis}

Three independent samples were analysed for each maturity degree and all the extraction and assays were carried out in triplicate. The results for each sample were expressed as mean values \pm standard deviation (SD) and were analysed using one-way analysis of variance (ANOVA) followed by Tukey's HSD Test with $\mathrm{p}=0.05$. Analyses were carried out using IBM SPSS Statistics for Windows, version 23.0 (IBM Corp., Armonk, New York, USA).

\section{Results and discussion}

\subsection{Phytochemical characterization of Hovenia dulcis pseudofruits}

\subsubsection{Hydrophilic compounds}

There is little information about the phenolic composition of Hovenia dulcis. The presence of four flavonoids, i.e., myricetin, quercetin, ampelopsin (dihydromyricetin) and taxifolin (dihydroquercetin) was described by Park, Kim, Rehman, Na, and Yoo (2015) in the fruit-stalk of Hovenia dulcis. Myricetin was also isolated from Hovenia dulcis fruits (Guo et al., 2015), as well as dihydromyricetin from fruits (Pinto et al., 2014; Yoo, Mun, \& Kim, 2006) and leaves (Chaturvedula \& Ruo, 2013). Various flavonol glycosides derived from kaempferol and quercetin have also been identified in the leaves (Cho, Hyun, Moon, \& Park, 2013), and up to eigth phenolic compounds, including phenolic acids (vanillic, ferulic and trihydrobenzoic acid), flavan-3-ols (catechin and afzelechin), aromadendrin (a dihydroflavonol), 3,5-dihydroxystilbene, and methyl vanillate have been found in $H$. dulcis stem bark (Li et al., 2005).

In the present study, thirteen individual phenolic compounds were detected and tentatively identified in the extracts prepared from Hovenia dulcis peduncles (Table 1; Fig. 2): three flavan-3ols, eight flavonols, one flavanone and one dihydrochalcone.

Peaks 1, 2 and 4 corresponded to flavan-3-ols. Peak 4 was positively identified as $(+)$-catechin by comparison with a commercial standard, whereas peak 1 , the major compound found in samples Hd02, Hd04 and Hd05, was assigned as (epi)gallocatechin based on its absorption and mass spectra. The pseudomolecular ion of peak $2[\mathrm{M}-\mathrm{H}]^{-}$at $m / z 593$ was coherent with a proanthocyanidin (PA) dimer consisted of a gallocatechin (GC) and a catechin (C). The observation of an $\mathrm{MS}^{2}$ fragment ion at $m / z 423(-170 \mathrm{mu})$ from the Retro Diels-Alder (RDA) cleavage of a GC suggested that this was located in the upper subunit of the dimer, as the RDA has been indicated to occur preferentially in that unit (de Pascual et al., 2000; Friedrich, Eberhardt, \& Galensa, 2000; Gu et al., 2003). Nevertheless, mass spectra do not allow to conclude about the precise identity of the units, whether (gallo)catechin or epi(gallo)catechin, so that peak 2 was tentatively identified as a prodelphinidin dimer (GC-C).

Peak 3 presented a pseudomolecular ion $[\mathrm{M}-\mathrm{H}]^{-}$at $\mathrm{m} / \mathrm{z} 595$ releasing $\mathrm{MS}^{2}$ fragment ions corresponding to losses of 90 and $120 \mathrm{mu}$ characteristic of C-glycosylated flavonoids (Cuyckens \& Claeys, 2004; Ferreres, Silva, Andrade, Seabra, \& Ferreira, 2003). A compound with similar mass and fragmentation pattern was identified in Spirodela polyrrhiza (Qiao et al., 2011) and Cyclopia subternata (de Beer et al., 2012) as 5,7,4'-trihydroxyflavanone-6,8 -di-C-glucoside (i.e. naringenin-6,8-di-C-glucoside). Since no further elements to identify the type of aglycone and sugar sub- 
Table 1

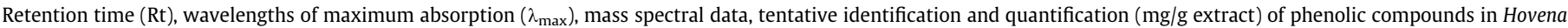
dulcis Thunb. pseudofruits at different maturity stages (means $\pm \mathrm{SD}, \mathrm{n}=9$ ).

\begin{tabular}{|c|c|c|c|c|c|c|c|c|c|c|}
\hline Peak & $\begin{array}{l}\text { Rt } \\
(\min )\end{array}$ & $\lambda_{\max }(\mathrm{nm})$ & $\begin{array}{l}\text { Molecular } \\
\text { ion }[\mathrm{M}- \\
\mathrm{H}]^{-}(\mathrm{m} / \mathrm{z})\end{array}$ & $\operatorname{MS}^{2}(m / z)$ & $\begin{array}{l}\text { Tentative } \\
\text { identification }\end{array}$ & Hd01 & Hd02 & Hd03 & $\mathrm{Hd} 04$ & Hd05 \\
\hline 1 & 5.0 & 278 & 305 & $\begin{array}{l}\text { 219(37), 177(16), 167(36), } \\
\text { 137(32), 125(65) }\end{array}$ & (Epi)gallocatechin ${ }^{1}$ & $2.9 \pm 0.3$ & $3.8 \pm 0.1$ & $1.1 \pm 0.1$ & $5.5 \pm 0.1$ & $21.3 \pm 0.4$ \\
\hline 2 & 6.0 & 276 & 593 & $423(78), 305(100), 289(27)$ & $\begin{array}{l}\text { Prodelphinidin dimer } \\
(\mathrm{GC}-\mathrm{C})^{\mathrm{a}, 1}\end{array}$ & $1.60 \pm 0.04$ & $1.45 \pm 0.01$ & $0.9 \pm 0.1$ & $1.3 \pm 0.1$ & $1.40 \pm 0.01$ \\
\hline 3 & 7.2 & $293,342 \mathrm{sh}$ & 595 & $\begin{array}{l}\text { 577(8), 505(18), 487(8), } 475 \\
(33), 457(19), 415(25), 385 \\
(54), 355(53), 343(3), 313(8)\end{array}$ & $\begin{array}{l}\text { Trihydroxyflavanone } \\
\text { di-C-glucoside }{ }^{2}\end{array}$ & $3.3 \pm 0.2$ & $2.6 \pm 0.2$ & $3.17 \pm 0.01$ & $1.66 \pm 0.01$ & $1.2 \pm 0.1$ \\
\hline 4 & 7.8 & 280 & 289 & $\begin{array}{l}245(10), 203(9), 187(6), 161 \\
(4), 137(22)\end{array}$ & $(+)$-Catechin ${ }^{1}$ & $0.8 \pm 0.1$ & $0.7 \pm 0.1$ & $0.22 \pm 0.01$ & nd & nd \\
\hline 5 & 14.7 & 356 & 431 & $\begin{array}{l}\text { 385(4), 367(20), 221(8), } 205 \\
(100), 187(13), 161(4), 131 \\
(11)\end{array}$ & Unknown flavonoid ${ }^{3}$ & $0.46 \pm 0.01$ & $0.01 \pm 0.01$ & $0.27 \pm 0.02$ & $\operatorname{tr}$ & $\operatorname{tr}$ \\
\hline 6 & 15.8 & 354 & 625 & $317(100)$ & $\begin{array}{l}\text { Myricetin-O- } \\
\text { rutinoside }^{3}\end{array}$ & $0.48 \pm 0.01$ & $\operatorname{tr}$ & $0.17 \pm 0.02$ & $\operatorname{tr}$ & $0.14 \pm 0.03$ \\
\hline 7 & 16.5 & 344 & 479 & $317(100)$ & $\begin{array}{l}\text { Myricetin-O- } \\
\text { glucoside }\end{array}$ & $\operatorname{tr}$ & nd & $\operatorname{tr}$ & $\operatorname{tr}$ & $0.22 \pm 0.01$ \\
\hline 8 & 16.9 & 356 & 771 & $301(100)$ & $\begin{array}{l}\text { Quercetin-O- } \\
\text { rutinosyl-glucoside }\end{array}$ & $1.13 \pm 0.04$ & $0.10 \pm 0.01$ & $0.61 \pm 0.02$ & $0.14 \pm 0.01$ & $0.11 \pm 0.02$ \\
\hline 9 & 17.6 & 356 & 771 & $301(100)$ & $\begin{array}{l}\text { Quercetin-O- } \\
\text { rutinosyl-glucoside }^{3}\end{array}$ & $2.76 \pm 0.02$ & $0.22 \pm 0.01$ & $1.11 \pm 0.03$ & $0.50 \pm 0.04$ & $0.51 \pm 0.02$ \\
\hline 10 & 18.6 & $284,336 \mathrm{sh}$ & 597 & $\begin{array}{l}\text { 579(13), 507(14), 489(17), } \\
477(67), 459(29), 417(67), \\
387(95), 357(100), 315(16)\end{array}$ & $\begin{array}{l}\text { Phloretin- } 3^{\prime}, 5^{\prime}-\text { di-C- } \\
\beta \text {-glucoside }\end{array}$ & $1.5 \pm 0.1$ & $0.46 \pm 0.03$ & $0.95 \pm 0.01$ & nd & nd \\
\hline 11 & 19.1 & 356 & 609 & $301(100)$ & $\begin{array}{l}\text { Quercetin-3-O- } \\
\text { rutinoside }^{3}\end{array}$ & $0.88 \pm 0.00$ & $\operatorname{tr}$ & $0.28 \pm 0.03$ & $\operatorname{tr}$ & $0.04 \pm 0.03$ \\
\hline 12 & 20.5 & 352 & 463 & $301(100)$ & $\begin{array}{l}\text { Quercetin-3-O- } \\
\text { glucoside }\end{array}$ & $0.37 \pm 0.00$ & $\operatorname{tr}$ & $0.050 \pm 0.001$ & $\operatorname{tr}$ & $\operatorname{tr}$ \\
\hline \multirow[t]{2}{*}{13} & 20.9 & 356 & 785 & $315(100)$ & $\begin{array}{l}\text { Isorhamnetin-O- } \\
\text { rutinosyl-glucoside }^{6}\end{array}$ & $0.50 \pm 0.01$ & $\operatorname{tr}$ & $0.03 \pm 0.01$ & $\operatorname{tr}$ & $\operatorname{tr}$ \\
\hline & & & & & $\begin{array}{l}\text { Total phenolics } \\
\text { compounds }\end{array}$ & $16.6 \pm 0.2 b$ & $9.3 \pm 0.4 c$ & $9.0 \pm 0.3 c$ & $9.2 \pm 0.1 c$ & $24.7 \pm 0.3 a$ \\
\hline
\end{tabular}

a $\mathrm{C}$ : (epi)catechin, GC: (epi)gallocatechin. tr-taces; nd-not detected. Phenolic compounds standards used for the quantification: $1-$ catechin $\left(\mathrm{y}=131.65 \mathrm{x}+4.11 ; \mathrm{R}^{2}=0.999\right)$,

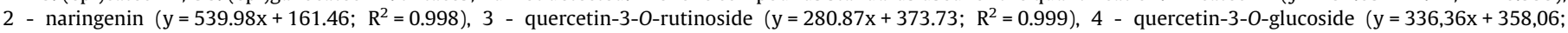

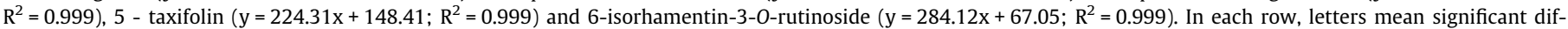
ferences between stages of maturation $(p<0.05)$.

stituents, peak 3 was tentatively assigned as a C-dihexosyltrihydroxyflavanone.

Peaks 5-9 and 11-13 showed absorption spectra characteristic of flavonols, which represented the largest group of phenolic compounds found in $\mathrm{H}$. dulcis samples. The absorption spectrum of peak 5 pointed to a flavonol and a compound with the same pseudomolecular ion ([M-H $]^{-}$at $\left.m / z 431\right)$ was found by Cho et al. (2013) in $\mathrm{H}$. dulcis leaves and identified as kaempferol-3-O-rhamnoside; nevertheless, the fragmentation pattern of the compound obtained in our case was not coherent with that identity, with no fragments that could be associated to the aglycone. Thus, the identity of peak 5 remains controversial being just designed as an unknown flavonoid. Peaks 11 (quercetin-3-O-rutinoside) and 12 (quercetin-3-Oglucoside) were positively identified by comparison of their retention, mass and UV-vis characteristics with commercial standards. Similarly, peaks 6 ([M-H]- at $m / z 625)$ and 7 ([M-H]- at $m / z 479)$, yielding a unique $\mathrm{MS}^{2}$ fragment at $m / z 317$ (myricetin) from the loss of $308 \mathrm{mu}$ and $162 \mathrm{mu}$, respectively, were tentatively assigned to myricetin-O-rutinoside and myricetin-O-glucoside. Peaks 8 and 9 possessed the same pseudomolecular ion $[\mathrm{M}-\mathrm{H}]^{-}$at $m / z 771$ releasing a unique $\mathrm{MS}^{2}$ fragment ion at $m / z 301$ associated to quercetin, coherent with the loss of two hexosyl and one deoxyhexosyl residues. The fact that the three sugar moieties are released simultaneously to produce one daughter ion suggested that they were forming a trisaccharide. Although no information could be obtained about the nature and location of the sugar residues, they were tentatively identified as two possible quercetin-O-rutinosylglucosides. The presence of a kaempferol-3-O-rutinosyl-glucoside (i.e., $3-0-\alpha$-L-rhamnopyranosyl- $(1 \rightarrow 6)-0$ - $\beta$-D-glucopyranosyl- $(1 \rightarrow$ $2)-O$ - $\beta$-D-glucopyranoside) was previously reported in the leaves of $H$. dulcis by Cho et al. (2013). Similar substitution pattern was observed for peak $13\left([\mathrm{M}-\mathrm{H}]^{-}\right.$at $\left.m / z 785\right)$, although releasing a fragment at $m / z 315$, corresponding to a methylquercetin, so that the compound was tentatively assigned as isorhamnetin $O$-rutinosylglucoside.

Finally, peak $10\left([\mathrm{M}-\mathrm{H}]^{-}\right.$at $m / z$ 597) also presented a fragmentation pattern consistent with C-glycosyl moieties. A compound with similar absorption and mass spectrum was identified as the dihydrochalcone phloretin-3',5'-di-C- $\beta$-glucoside in Citrus species (Barreca, Bellocco, Caristi, Leuzzi, \& Gattuso, 2011; Roowi \& Crozier, 2011) and Cyclopia subternata (de Beer et al., 2012), identity was also tentatively assumed in our case.

Quantitatively, $H$. dulcis pseudofruits in the last maturity stage (Hd05) presented the highest total phenolic compounds, mainly due to the presence of (epi)catechin, followed by Hd01, sample that gave the highest content of all the remaining phenolic compounds detected. The astringency of unripe or immature pseudofruits is a consequence of the presence of intermediate molecular weight tannins, mainly "condensed or hydrolysables tanning agents" (mostly catechins and proanthocyanidins), that reduce its content during ripening process, mainly due to complexation (with fiber or proteins) and polymerisation processes (Belitz, Grosh, \& Schieberle, 2009; Ozawa, Lilley, \& Haslam, 1987), this fact was observed in persimmon fruits and dwarf cashew pseudofruits (de Figueiredo, Lajolo, Alves, \& Filgueiras, 2002; Del Bubba et al., 2009). This could also explain the reduction in catechins 

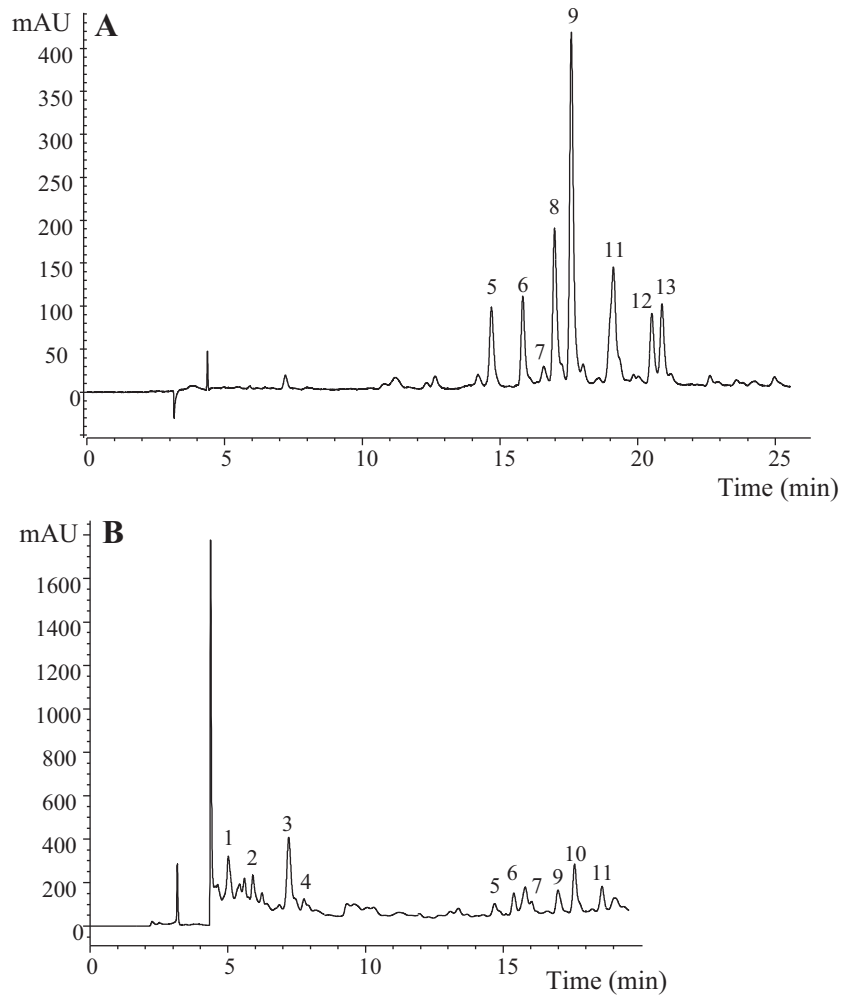

Fig. 2. Phenolic compounds profile of Hovenia dulcis Thunb. pseudofruits in the immature stage (Hd01) recorded at $370 \mathrm{~nm}(\mathrm{~A})$ and $280 \mathrm{~nm}$ (B).

(flavan-3-ols) in the samples studied herein. Moreover, other important effect observed during pseudofruits maturity was the increase in (epi)gallocatechin (caracteristic compound present in black tea) which is normally synthesized after flavonols oxidation (polyphenoloxidase reaction) and polymerization process (Belitz et al., 2009), this fact could also explain the reduction in catechin and flavonols content (mainly quercetin derivatives) during ripening process.

\subsubsection{Lipophilic compounds}

Fatty acid and tocopherol profiles of the analysed pseudofruits are shown in Table 2. Saturated fatty acids (SFA) were the predominant lipid fraction at all maturity stages (average values of 44.45 - 58.60\%), being palmitic acid (C16:0) the predominant one. The highest relative percentage was observed in the most immature stages (Hd01), decreasing the content along the ripening process. Ding, Liang, and Teng (1997) also reported SFA as predominated fatty acids $(87.46 \%)$ in $\mathrm{H}$. dulcis seeds. Polyunsaturated fatty acids (PUFA) fraction with linoleic acid as the major one (LA, C18:2n6) increased during ripening process, being observed the highest relative percentages in Hd04 (PUFA: 51.70\%; LA: 35.90\%), which is consider as mature being the most suitable moment for consumption. In an overview, MUFA were the lowest lipids present, while both SFA and PUFA showed similar concentrations.

Total tocopherols increased during ripening process, as happened with fatty acids, being the highest values observed in Hd04 (5.66 mg/100 g dw; Table 2). All forms were identified in the studied peduncles, except $\delta$-tocopherol in Hd05 pseudofruits. $\alpha$-Tocopherol was the major form in all ripening stages, being the highest value observed in Hd04 (5.43 mg/100 g dw). To the authors best of knowledge, this is the first report about tocopherols content in $H$. dulcis peduncles.

\subsection{Bioactive properties of Hovenia dulcis pseudofruits}

\subsubsection{Antioxidant activity}

Antioxidant mechanisms in biological tissues are extremely complex, and there is not one method that can provide unequivocal results (Carocho \& Ferreira, 2013). Thus, the antioxidant capacity of $H$. dulcis peduncles (hydromethanolic extracts) was evaluated by three different in vitro assays. DPPH scavenging activity and reducing power (Ferricyanide/Prussian blue assay) were used to evaluate total antioxidant capacity, while $\beta$-carotene/ linoleate assay was applied to determine the inhibition of lipid peroxidation process. The evolution of antioxidant capacity during ripening process can be observed in Table 3. Regarding total antioxidant capacity, the most immature peduncles (Hd01) presented higher antioxidant properties (lower $\mathrm{EC}_{50}$ values) comparing with the peduncles at mature stages, mainly Hd04. This could probably be explained by the presence of the highest phenolic compounds concentration, with the exception of (epi)gallocatechin, which was higher in Hd05, than in the maturity stage (Hd01). A trend of decreasing (from Hd01 to Hd04) and increasing (from Hd04 to Hd05) in the antioxidant capacity was detected using these methods. To the authors best knowledge, this is the first report of lipid peroxidation inhibition process in $\mathrm{H}$. dulcis pseudofruits, the mature peduncle (Hd04) presented the highest antioxidant capacity comparing with the other ripening stages; probably, this tendency could be related with the increasing content of PUFA and tocopherols observed during the ripening process. Since PUFA and particularly tocopherols are involved in lipid peroxidation process. The most important biological role of vitamin $\mathrm{E}$ is to protect PUFA, other components of cell membranes, and LDL, from oxidation by free radicals, and it is particularly effective in preventing lipid peroxidation, limiting the accumulation of high levels of products derived from this process that are associated with numerous diseases and clinical conditions. Its action as an antioxidant is due to the donation of a hydrogen atom to peroxyl radicals of unsaturated lipid molecules, forming a hydroperoxide and a tocopheroxyl radical, which reacts with peroxyl radicals forming more stable adducts (Duthie, 1993; Nogala-Kalucka, Kupczyk, Polewski, Siger, \& Dwiecki, 2007).

A similar trend was observed in the same samples using other different antioxidant assays (ABTS and FRAP methods), as reported by Maieves et al. (2015b). In that study total antioxidant capacity decreased from Hd01 to Hd03, being closely related with total polyphenol contents (evaluated as families of compounds).

Hu, Lee, and Wang (2010) evaluated the DPPH scavenging activity of matured $H$. dulcis fruit extracts obtaoned using different solvents (water, hot water, methanol and ethyl acetate), and reported $12.72 \%$ at $100 \mu \mathrm{g} / \mathrm{mL}$ for the methanolic extract. Basavegowda, Idhayadhulla, and Lee (2014) also described interesting values for DPPH and FRAP assays in Golden nanoparticles made from $H$. dulcis fruits hot aqueous extract.

Other authors also reported antioxidant activity of other botanical parts of $H$. dulcis; Cho et al. (2013), described DPPH values of leaves extracts obtained using different solvents (e.g., methanol, ethanol, hot water, n-hexane) and their corresponding isolated compounds, being the ethanolic and methanolic extracts the ones with better results $\left(\mathrm{SC}_{50}\right.$ (50\% DPPH free radical scavenging concentration) was 83 and $112 \mu \mathrm{g} / \mathrm{mL}$, respectively). While, Li et al. (2005) reported DPPH and ABTS values of $H$. dulcis stem extracts (e.g., methanol, water, ethyl acetate), and the best results were obtained with the ethyl acetate stem extract $\left(\mathrm{IC}_{50}=18.3\right.$ and $4.9 \mu \mathrm{g} / \mathrm{mL}$ for DPPH and ABTS assays, respectively).

\subsubsection{Antitumor activity}

Table 3 presents the antitumor and hepatotoxic activity of the hydromethanolic extracts of $H$. dulcis at different stages of matura- 
Table 2

Fatty acids profile (relative percentage) and tocopherols content $(\mathrm{mg} / 100 \mathrm{~g} \mathrm{dw}$ ) of Hovenia dulcis Thunb. pseudofruits at different maturity stages (mean \pm SD, $\mathrm{n}=9$ ).

\begin{tabular}{|c|c|c|c|c|c|}
\hline & Hd01 & Hd02 & Hd03 & Hd04 & Hd05 \\
\hline \multicolumn{6}{|c|}{ Fatty acids profile (relative percentage) } \\
\hline C6:0 & $0.30 \pm 0.01$ & $0.100 \pm 0.001$ & $0.100 \pm 0.001$ & $0.25 \pm 0.03$ & $0.20 \pm 0.01$ \\
\hline $\mathrm{C} 8: 0$ & $0.45 \pm 0.05$ & $0.35 \pm 0.04$ & $0.25 \pm 0.05$ & $0.20 \pm 0.06$ & $0.15 \pm 0.03$ \\
\hline C10:0 & $0.45 \pm 0.05$ & $0.40 \pm 0.01$ & $0.25 \pm 0.05$ & $0.200 \pm 0.001$ & $0.15 \pm 0.03$ \\
\hline $\mathrm{C} 12: 0$ & $0.85 \pm 0.05$ & $0.70 \pm 0.01$ & $0.65 \pm 0.05$ & $0.50 \pm 0.01$ & $0.40 \pm 0.01$ \\
\hline C13:0 & nd & nd & $0.100 \pm 0.001$ & nd & $0.100 \pm 0.001$ \\
\hline C14:0 & $1.2 \pm 0.1$ & $1.15 \pm 0.05$ & $1.2 \pm 0.1$ & $1.1 \pm 0.1$ & $0.80 \pm 0.10$ \\
\hline $\mathrm{C} 15: 0$ & $0.50 \pm 0.01$ & $0.40 \pm 0.01$ & $0.50 \pm 0.01$ & $0.70 \pm 0.07$ & $0.40 \pm 0.06$ \\
\hline C16:0 & $38 \pm 1$ & $31.95 \pm 0.05$ & $30.85 \pm 0.05$ & $29.7 \pm 0.1$ & $30.8 \pm 0.3$ \\
\hline C16:1 & $0.25 \pm 0.05$ & $0.70 \pm 0.01$ & $0.70 \pm 0.07$ & $0.80 \pm 0.01$ & $0.85 \pm 0.09$ \\
\hline $\mathrm{C} 17: 0$ & $0.8 \pm 0.1$ & $0.70 \pm 0.01$ & $0.65 \pm 0.05$ & $0.60 \pm 0.01$ & $0.55 \pm 0.05$ \\
\hline C18:0 & $6.6 \pm 0.5$ & $5.8 \pm 0.4$ & $5.1 \pm 0.4$ & $4.55 \pm 0.05$ & $4.75 \pm 0.05$ \\
\hline C18:1n9 & $6.2 \pm 0.2$ & $5.95 \pm 0.05$ & $3.1 \pm 0.2$ & $3.10 \pm 0.01$ & $4.9 \pm 0.3$ \\
\hline $\mathrm{C} 18: 2 \mathrm{n} 6$ & $23 \pm 2$ & $30.05 \pm 0.05$ & $35.4 \pm 0.2$ & $35.9 \pm 0.3$ & $35.2 \pm 0.3$ \\
\hline C18:3n3 & $12 \pm 1$ & $14.9 \pm 0.2$ & $15.1 \pm 0.1$ & $15.5 \pm 0.1$ & $13.8 \pm 0.3$ \\
\hline C20:0 & $1.6 \pm 0.2$ & $1.1 \pm 0.1$ & $1.05 \pm 0.05$ & $1.10 \pm 0.01$ & $1.10 \pm 0.01$ \\
\hline C20:1 & nd & $0.30 \pm 0.06$ & nd & nd & nd \\
\hline$C 20: 3 n 3+C 21: 0$ & $0.45 \pm 0.05$ & $0.35 \pm 0.05$ & $0.25 \pm 0.05$ & $0.30 \pm 0.01$ & $0.30 \pm 0.01$ \\
\hline $\mathrm{C} 22: 0$ & $5.5 \pm 0.6$ & $3.1 \pm 0.1$ & $2.9 \pm 0.2$ & $3.45 \pm 0.05$ & $3.6 \pm 0.1$ \\
\hline C23:0 & nd & $0.40 \pm 0.01$ & $0.35 \pm 0.04$ & $0.40 \pm 0.01$ & $0.30 \pm 0.01$ \\
\hline $\mathrm{C} 24: 0$ & $2.75 \pm 0.05$ & $1.65 \pm 0.05$ & $1.7 \pm 0.1$ & $1.70 \pm 0.01$ & $1.85 \pm 0.05$ \\
\hline SFA & $59 \pm 3$ & $47.8 \pm 0.3$ & $45.7 \pm 0.6$ & $44.5 \pm 0.4$ & $45.1 \pm 0.2$ \\
\hline MUFA & $6.4 \pm 0.1$ & $6.95 \pm 0.05$ & $3.7 \pm 0.3$ & $3.90 \pm 0.01$ & $5.7 \pm 0.4$ \\
\hline PUFA & $35 \pm 3$ & $45.3 \pm 0.2$ & $50.7 \pm 0.2$ & $51.7 \pm 0.4$ & $49.2 \pm 0.5$ \\
\hline $\mathrm{n} 6 / \mathrm{n} 3$ & $1.91 \pm 0.05$ & $1.98 \pm 0.02$ & $2.30 \pm 0.01$ & $2.27 \pm 0.01$ & $2.50 \pm 0.03$ \\
\hline \multicolumn{6}{|c|}{ Tocopherols (mg/100 g dw) } \\
\hline$\alpha$ - tocopherol & $0.183 \pm 0.005 a$ & $2.71 \pm 0.02 b$ & $4.45 \pm 0.02 d$ & $5.43 \pm 0.06 e$ & $4.06 \pm 0.03 c$ \\
\hline$\beta$-tocopherol & $0.038 \pm 0.005 a$ & $0.104 \pm 0.009 d$ & $0.038 \pm 0.002 \mathrm{a}$ & $0.048 \pm 0.002 b$ & $0.088 \pm 0.003 c$ \\
\hline$\gamma$-tocopherol & $0.023 \pm 0.003 a$ & $0.074 \pm 0.004 b$ & $0.089 \pm 0.001 \mathrm{c}$ & $0.070 \pm 0.001 b$ & $0.069 \pm 0.004 b$ \\
\hline$\delta$-tocopherol & $0.052 \pm 0.009 b$ & $0.064 \pm 0.006 c$ & $0.037 \pm 0.002 a$ & $0.060 \pm 0.004 c$ & nd \\
\hline Total tocopherols & $0.30 \pm 0.01 \mathrm{a}$ & $2.96 \pm 0.01 b$ & $4.7 \pm 0.1 \mathrm{~d}$ & $5.7 \pm 0.1 \mathrm{e}$ & $4.24 \pm 0.05 c$ \\
\hline
\end{tabular}

nd - non-detected; dw - dry weight.

In each row, letters mean significant differences between stages of maturation $(p<0.05)$.

Table 3

Antioxidant and antitumor properties of the hydromethanolic extracts obtained from Hovenia dulcis Thunb. pseudofruits at different maturity stages (mean \pm SD, $\mathrm{n}=9$ ).

\begin{tabular}{|c|c|c|c|c|c|}
\hline & Hd01 & Hd02 & Hd03 & Hd04 & Hd05 \\
\hline \multicolumn{6}{|l|}{ Antioxidant activity $\left(E C_{50}, \mathrm{mg} / \mathrm{mL}\right)$} \\
\hline DPPH scavenging activity & $0.14 \pm 0.004 \mathrm{a}$ & $0.24 \pm 0.02 b$ & $1.6 \pm 0.2 \mathrm{c}$ & $3.58 \pm 0.04 \mathrm{e}$ & $3.0 \pm 0.1 \mathrm{~d}$ \\
\hline Ferricyanide/Prussian blue assay & $0.13 \pm 0.001 a$ & $0.20 \pm 0.003 b$ & $1.04 \pm 0.02 \mathrm{c}$ & $1.89 \pm 0.02 \mathrm{e}$ & $1.21 \pm 0.004 d$ \\
\hline$\beta$-carotene bleaching inhibition & $0.96 \pm 0.04 d$ & $0.53 \pm 0.01 c$ & $0.26 \pm 0.01 b$ & $0.140 \pm 0.001 \mathrm{a}$ & $0.28 \pm 0.01 b$ \\
\hline \multicolumn{6}{|l|}{ Antitumor activity ( $\mathrm{GI}_{50}$ values, $\mu \mathrm{g} / \mathrm{mL}$ ) } \\
\hline MCF-7 (breast carcinoma) & $247 \pm 5 a$ & $344 \pm 5 b$ & $>400$ & $>400$ & $>400$ \\
\hline NCI-H460 (non-small cell lung cancer) & $79 \pm 5 a$ & $110 \pm 9 b$ & $>400$ & $>400$ & $>400$ \\
\hline HeLa (cervical carcinoma) & $274 \pm 6 a$ & $323 \pm 21 b$ & $>400$ & $>400$ & $>400$ \\
\hline HepG2 (hepatocellular carcinoma) & $82 \pm 2 a$ & $216 \pm 0.1 b$ & $>400$ & $>400$ & $>400$ \\
\hline \multicolumn{6}{|l|}{ Hepatotoxicity ( $G I_{50}$ values, $\mu \mathrm{g} / \mathrm{mL}$ ) } \\
\hline PLP2 & $>400$ & $>400$ & $>400$ & $>400$ & $>400$ \\
\hline
\end{tabular}

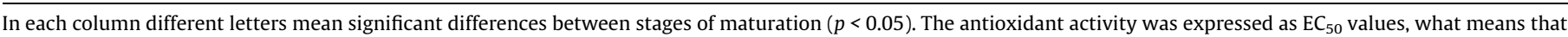

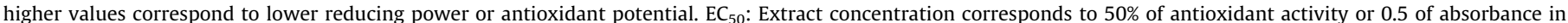

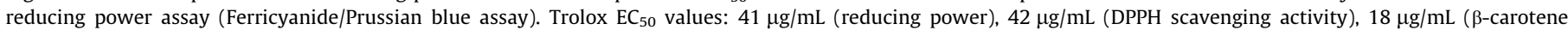

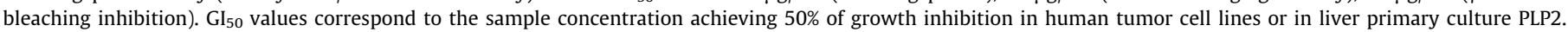
Ellipticine $\mathrm{GI}_{50}$ values: $1.21 \mu \mathrm{g} / \mathrm{mL}$ (MCF-7), $1.03 \mu \mathrm{g} / \mathrm{mL}$ (NCI-H460), $0.91 \mu \mathrm{g} / \mathrm{mL}$ (HeLa), $1.10 \mu \mathrm{g} / \mathrm{mL}$ (HepG2) and 2.29 (PLP2).

tion. Ellipticine, a very strong antitumor compound, which intercalates with DNA and inhibits topoisomerase II was used as a positive control, although it has the important disadvantage of being highly toxic also for non-tumor cells. The tested human tumor cell lines of breast, colon, cervical, and liver carcinoma are some of the most used for primary screening of antitumor potential. Only the most immature stages showed antitumor activity against all the tested cell lines; the lowest $\mathrm{GI}_{50}$ values were observed with Hd01 for HCT15 (colon carcinoma) and HepG2 (hepatocellular carcinoma) ( 78.58 and $82.34 \mu \mathrm{g} / \mathrm{mL}$, respectively). None of the extracts showed inhibition towards the non-tumor liver primary culture
(PLP2), corroborating that the use of these pseudofruits is safe at this level.

Other authors reported antitumor activity of $\mathrm{H}$. dulcis fruits and leaves against different tumor cell lines. Lee et al. (1999) reported that ethanol extract of $H$. dulcis fruits exhibited a potent growth inhibitory activity of Hep3B and MCF-7 cell lines, whereas this extract did not show considerable cytotoxicity on HEL299 cell lines. Castro et al. (2002) reported that ethanol extract of $H$. dulcis pseudofruits possessed high degree of selectivity against SP2/0 mouse myeloma and BW lymphoma cell in vitro. 
Table 4

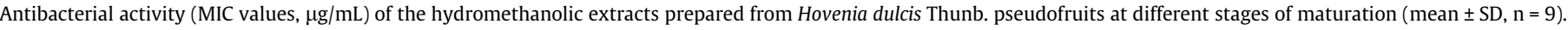

\begin{tabular}{|c|c|c|c|c|c|}
\hline Tested bacteria & Hd01 & Hd02 & Hd03 & Hd04 & Hd05 \\
\hline Enterococcus faecalis & $\mathrm{ni}$ & $\mathrm{ni}$ & 50 & 25 & 12.5 \\
\hline Pseudomonas aeruginosa & 3.12 & 6.25 & ni & 25 & 12.5 \\
\hline Streptococcus epidermidis & 25 & 25 & ni & 50 & 25 \\
\hline Staphylococcus aureus & 6.25 & 6.25 & ni & 25 & 25 \\
\hline Escherichia coli & ni & ni & ni & 50 & 25 \\
\hline
\end{tabular}

ni - no inhibition; MIC - minimal inhibitory concentration.

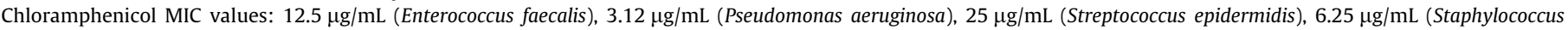
aureus) and $25 \mu \mathrm{g} / \mathrm{mL}$ (Escherichia coli).

\subsubsection{Antimicrobial activity}

According to the World Health Organisation (WHO, 2014) the bacterial infections which contribute most to human disease are also those in which emerging and microbial resistance is most evident, such as, diarrheal diseases, respiratory tract infections, meningitis, and hospital-acquired (nosocomial) infections. The following are some common examples of bacteria species; penicillin-resistant Streptococcus pneumoniae, methicillinresistant Staphylococcus aureus, and multi-resistant Salmonellae and the resistant Escherichia Coli, among others. All of them responsible of relevant illness such as bloody diarrhea, abdominal cramps, nausea, vomiting, and fever are the symptoms caused by E. coli 0157:H7 haemorrhagic colitis. Other important bacteria's commonly responsible of food intoxication are Staphylococcus aureus, whose enterotoxin include diarrhea, abdominal cramps, nausea, and vomiting (de Camargo, Regitano-d'Arce, Gallo, \& Shahidi, 2015).

To the authors best knowledge, antimicrobial studies of $H$. dulcis pseudofruits are scarce; only Cho, Moon, and Park (2000), Cho, Moon, Eun, Chung, and Park (2004) and Basavegowda et al. (2014) reported antimicrobial activity of pseudofruits extracts. Other authors reported antiparasitic and antimicrobial activity of different extracts from other botanical parts of $\mathrm{H}$. Dulcis. Therefore, Gadelha et al. (2005) reported that the dichloromethane fraction from the methanol extract of $H$. dulcis leaves inhibited the growth of Giardia lamblia trophozoites ( $\mathrm{IC}_{50}=12 \mu \mathrm{g} / \mathrm{mL}$ ). Also, Castro et al. (2002) reported that the activity of the aqueous extracts of fruit stalks and methanolic extracts of leaves from seedlings of $\mathrm{H}$. dulcis could inhibit the multiplication of Trypanosoma cruzi. Moreover, the hot water extracts from leaves and stems of $H$. dulcis have shown antimicrobial activity against Gram-positive and Gramnegative bacteria, and yeast (Cho, Moon, Eun, Chung, \& Park, 2004; Cho, Moon, \& Park, 2000).

In the present study, pseudofruits phenolic extracts were evaluated against different Gram positive and Gram negative bacteria, namely Escherichia coli, Enterococcus faecalis, Pseudomonas aeruginosa, Staphylococcus epidermidis and Staphylococcus aureus (Table 4). In general terms, the antimicrobial activity in the analysed samples was severely influenced by the maturation process. The most immature stages (Hd01 and Hd02) presented higher activity (lower MIC values), as observed for Staphylococcus epidermidis, Sthaphylococcus aureus and Pseudomonas aeruginosa, although no growth inhibition was observed for Enterococcus faecalis and Escherichia coli. On the other hand, the highest MIC values were observed with Hd04 for all tested bacteria. The stage of maturation $\mathrm{HdO} 3$ only inhibited the growth inhibition of Enterococccus faecalis, at a concentration of $50 \mu \mathrm{g} / \mathrm{mL}$.

Numerous research groups have sought to elucidate the antibacterial mechanisms of action of selected flavonoids. The activity of quercetin, for example, has been at least partially attributed to inhibition of DNA gyrase. It has also been proposed that sophoraflavone $G$ and (-)-epigallocatechin gallate inhibit cytoplasmic membrane function, and that licochalcones $A$ and $C$ inhibit energy metabolism. Other flavonoids whose mechanisms of action have been investigated include robinetin, myricetin, apigenin, rutin, galangin, 2,4,2'-trihydroxy-5'-methylchalcone and lonchocarpol A (Cushnie \& Lamb, 2005). The antiomicrobial activity of the evaluated extract could be related with the flavonoids content. From the obtained results, it can be seen that the better antibacterial activity, mainly against Pseudomonas aeruginosa and Staphylococcus aureus, was observed in Hd01 sample (the most immature pseudofruit stage), which present the highest catechin and quercetin derivatives content. Otherwise, for Enterococcus faecalis, the better antibacterial results was observed in the most mature pseudofruit stage (Hd05) which present the highest (Epi)gallocatechin content $(21.3 \mathrm{mg} / \mathrm{g}$ extract).

Our results were according with those reported by Cho et al. (2000) in H. dulcis pseudofruits extract, against Staphylococcus aureus, Staphylococcus epidermidis, Bacillus subtilis, Micrococcus luteus, Pediococcus damnosus, Escherichia coli, Pseudomonas aeruginosa and Salmonella typhi.

Generally, phenolic content tends to be higher in immature fruits since they are utilized as secondary metabolites for defence mechanisms of the plants, and thus they protect young fruits and allow their maturation and reproduction function (Fennema, 1996). Different compounds have been previously reported in the methanolic extracts of $\mathrm{H}$. dulcis to provide antimicrobial effects. In this way, extracts from $H$. dulcis leaves showed antimicrobial activity against Staphylococcus aureus and Escherichia coli (Cho et al., 2004), being 3(Z)-dodecenedioic acid the antimicrobialactive compound isolated in these leaves. Furthermore, Cho et al. (2000) described that the methanolic fraction of hot-water extract of $H$. dulcis showed antioxidant and antimicrobial properties. Vanillic acid and ferulic acid were isolated from this fraction, and exhibited antimicrobial activity against Gram negative and Gram positive bacteria, and yeasts.

\section{Conclusions}

This is the first study on individual phenolic compounds, fatty acids and tocopherols, as well as antitumor and antibacterial activity of $H$. dulcis pseudofruits through the maturation process. This underutilized product demonstrated to be a rich source of these bioactive compounds showing antioxidant, antitumor and antibacterial properties with an interesting activity in the immature stages (Hd01 and Hd02). This study supports the potential application of $\mathrm{H}$. dulcis peduncles as alternative bioactive ingredients for functional foods, dietary supplements or nutraceuticals.

\section{Acknowledgements}

The authors are grateful to the Foundation for Science and Technology (FCT, Portugal) and FEDER under Programe PT2020 for financial support to CIMO (UID/AGR/00690/2013), LSRE (Project UID/EQU/50020/2013), H. Maieves (CAPES/PDSE and BEX 3480/13-5), L. Barros (SFRH/BPD/107855/2015), R.C. Calhelha (SFRH/BPD/BPD/68344/2010) and I. Dias (SFRH/BD/84485/2012) grants. 


\section{References}

Abreu, R. M. V., Ferreira, I. C. F. R., Calhelha, R. C., Lima, R. T., Vasconcelos, M. H., \& Adega, F. (2011). Anti-hepatocellular carcinoma activity using human HepG2 cells and hepatotoxicity of 6-substituted methyl 3-aminothieno[3,2-b]pyridine2-carboxylate derivatives: In vitro evaluation, cell cycle analysis and QSAR studies. European Journal of Medical Chemistry, 46, 5800-5806.

Barreca, D., Bellocco, E., Caristi, C., Leuzzi, U., \& Gattuso, G. (2011). Kumquat (Fortunella japonica Swingle) juice: Flavonoid distribution and antioxidant properties. Food Research International, 44, 2190-2197.

Barros, L., Pereira, E., Calhelha, R. C., Dueñas, M., Carvalho, A. M., Santos-Buelga, C., et al. (2013). Bioactivity and chemical characterization in hydrophilic and lipophilic compounds of Chenopodium ambrosioides L.. Journal of Functional Foods, 5, 1732-1740.

Basavegowda, N., Idhayadhulla, A., \& Lee, Y. R. (2014). Phyto-synthesis of gold nanoparticles using fruit extract of Hovenia dulcis and their biological activities. Industrial Crops and Products, 52, 745-751.

Belitz, H. D., Grosh, W., \& Schieberle, P. (2009). Food chemistry (4th ed.). Berlin Heidelberg: Springer-Verlag.

Carocho, M., Barros, L., Calhelha, R. C., Ćirić, A., Soković, M., Santos-Buelga, C., et al. (2015). Melissa officinalis L. decoctions as functional beverages: A bioactive approach and chemical characterization. Food E' Function, 6, 2240-2248.

Carocho, M., \& Ferreira, I. C. F. R. (2013). A review on antioxidants, prooxidants and related controversy: Natural and synthetic compounds, screening and analysis methodologies and future perspectives. Food and Chemical Toxicology, 51, $15-25$.

Carvalho, P. E. R. (1994). Ecologia, silvicultura e usos da uva-do-japão (hoveniadulcis thunberg) (pp. 24-65). Colombo: EMBRAPA Florestas.

Castro, T. C., Pelliccione, V. L. B., Figueiredo, M. R., Soares, R. O. A., Bozza, M. T., Viana, V. R. C., et al. (2002). Atividade antineoplásica e tripanocida de Hovenia dulcis Thunb. cultivada in vivo e in vitro. Revista Brasileira de Farmacognosia, 12, 96-99.

Cha, B. C., Lee, E. H., Lee, E., \& Park, H. H. (2004). Activity of glutathione S-transferase and effect of alcohol decomposition on the fruit of Hovenia dulcis Thunb. Yakhak Hoeji, 48, 213-217.

Chaturvedula, V. S. P., \& Ruo, H. (2013). Isolation and NMR spectral studies of dihydromyricetin. Journal of Pharmacognosy and Phytochemistry, 2, 113-115.

Chitarra, M. I. F., \& Chitarra, A. B. (2005). Pós-colheita de frutos e hortaliças: Fisiologia e manuseio (2nd ed.). Lavras: UFLA.

Cho, J. Y., Hyun, S. H., Moon, J. H., \& Park, K. H. (2013). Isolation and structural determination of a novel flavonol triglycoside and 7 compounds from the leaves of oriental raisin tree (Hovenia dulcis) and their antioxidative activity. Food Science and Biotechnology, 22, 115-123.

Cho, J. Y., Moon, J. H., Eun, J. B., Chung, S. J., \& Park, K. H. (2004). Isolation and Characterization of 3(Z)-Dodecenedioic Acid as an Antibacterial Substance from Hovenia dulcis Thunb. Food Sciences and Biotechnology, 13, 46-50.

Cho, J. Y., Moon, J. H., \& Park, K. H. (2000). Isolation and identification of 3-methoxy4-hydroxybenzoic acid and 3-methoxy-4-hydroxycinnamic acid from hot water extracts of Hovenia dulcis Thunb and confirmation of their antioxidative and antimicrobial activity. KoSFOST, 32, 1403-1408.

Cushnie, T. P., \& Lamb, A. J. (2005). Antimicrobial activity of flavonoids. International Journal of Antimicrobial Agents, 26(5), 343-356.

Cuyckens, F., \& Claeys, M. (2004). Mass spectrometry in the structural analysis of flavonoids. Journal of Mass Spectrometry, 39, 1-15.

de Beer, D., Schulze, A. E., Joubert, E., de Villiers, A., Malherbe, C. J., \& Stander, M. A. (2012). Food ingredient extracts of Cyclopia subternata (Honeybush): Variation in phenolic composition and antioxidant capacity. Molecules, 17, 14602-14624.

de Camargo, A. C., Regitano-d'Arce, M. A. B., Gallo, C. R., \& Shahidi, F. (2015) Gamma-irradiation induced changes in microbiological status, phenolic profile and antioxidant activity of peanut skin. Journal of Functional Foods, 12, 129-143.

de Figueiredo, R. W., Lajolo, F. M., Alves, R. E., \& Filgueiras, H. A. C. (2002). Physicalchemical changes in early dwarf cashew pseudofruits during development and maturation. Food Chemistry, 77(3), 343-347.

de Pascual-Teresa, S., Santos-Buelga, C., \& Rivas-Gonzalo, J. G. (2000). Quantitative analysis of flavan-3-ols in Spanish foodstuffs and beverages. Journal of Agricultural and Food Chemistry, 48, 5331-5337.

Del Bubba, M., Giordani, E., Pippucci, L., Cincinelli, A., Checchini, L., \& Galvan, P. (2009). Changes in tannins, ascorbic acid and sugar content in astringent persimmons during on-tree growth and ripening and in response to different postharvest treatments. Journal of Food Composition and Analysis, 22(7), 668-677.

Ding, L. S., Liang, Q. L., \& Teng, Y. F. (1997). Study on flavonoids in seeds of Hovenia dulcis. Acta Pharmaceutica Sinica, 32, 600-602.

Duarte, M. C. T., Figueira, G. M., Sartoratto, A., Rehder, V. L. G., \& Delarmelina, C. (2005). Anti-Candida activity of Brazilian medicinal plants. Journal of Ethnopharmacology, 97, 305-311.

Duthie, G. G. (1993). Lipid peroxidation. European Journal of Clinical Nutrition, 47 (11), 759.

Fennema, O. R. (1996). Food chemistry (3rd ed.). New York: Marcel Dekkan.

Ferreres, F., Silva, B. M., Andrade, P. B., Seabra, R. M. \& Ferreira, M. A. (2003). Approach to the study of C-glycosyl flavones by ion trap HPLC-PAD-ESI/MS/MS: Application to seeds of quince (Cydonia oblonga). Phytochemical Analysis, 14, 352-390.
Friedrich, W., Eberhardt, A., \& Galensa, R. (2000). Investigation of proanthocyanidins by HPLC with electrospray ionization mass spectrometry. European Food Research and Technology, 211, 56-64.

Gabrielson, J., Hart, M., Jarelöv, A., Kuhn, I., Mckenzie, D., \& Möllby, R. (2002). Evaluation of redox indicators and the use of digital scanners and spectrophotometer for quantification of microbial growth in microplates. Journal of Microbiological Methods, 50, 63-73.

Gadelha, A. P. R., Vidal, F., Castro, T. M., Lopes, C. S., Albarello, N., Coelho, M. G. P., et al. (2005). Susceptibility of Giardia lamblia to Hovenia dulcis extracts. Parasitology Research, 97(5), 399-407.

Gu, L., Kelm, M. A., Hammerstone, J. F., Zhang, Z., Beecher, G., Holden, J., et al. (2003). Liquid chromatographic/electrospray ionization mass spectrometric studies of proanthocyanidins in foods. Journal of Mass Spectrometry, 38, 1272-1280.

Guo, J., Meng, Y., Zhao, Y., Hu, Y., Ren, D., \& Yang, X. (2015). Myricetin derived from Hovenia dulcis Thunb. ameliorates vascular endothelial dysfunction and liver injury in high choline-fed mice. Food E' Function, 6, 1620-1634.

Hase, K., Ohsugi, M., Xiong, Q., Basnet, P., Kadota, S., \& Namba, T. (1997). Hepatoprotective effect of Hovenia dulcis THUNB. on experimental liver injuries induced by carbon tetrachloride or D-galactosamine/ lipopolysaccharide. Biological and Pharmaceutical Bulletin, 20(4), 381-385.

Hu, W., Lee, K. Y., \& Wang, M. H. (2010). Antioxidant activities of various extracts of Hovenia dulcis Thunb fruits. Korean Journal of Plant Resources, 23(3), 207-213.

Hung, R. J., Yazdani, U., Yoon, J., Wu, H., Yang, T., Gupta, N., et al. (2010). Mical links semaphorins to F-actin disassembly. Nature, 463, 823-827.

Hyun, T. K., Eom, S. H., Yu, C. Y., \& Roitsch, T. (2010). Hovenia dulcis - An Asian traditional herb. Planta Medica, 76, 943-949.

Ji, Y., Yang, P., \& Li, J. (2000). Preventive effect of Hovenia dulcis Thunb on alcoholinduced liver injury. Pharmacology and Clinics of Chinese Material Medica, 6, 9-20.

Kiyoshi, S. (1987). Effect of water extracts of crude drugs in decreasing blood alcohol concentration in rats. Chemical Pharmacology Bulletin, 35, 4597-4604.

Lee, M. K., Kim, Y. G., An, S. W., Kim, M. H., Lee, J. H., \& Lee, H. Y. (1999). Biological activities of Hovenia dulcis Thunb. Korean Journal of Medicinal Crop Science, 7, 185-192.

Li, G., Min, B. S., Zheng, C., Lee, J., Oh, S. R., Ahn, K. S., et al. (2005). Neuroprotective and free radical scavenging activities of phenolic compounds from Hovenia dulcis. Archives of Pharmacal Research, 28, 804-809.

Maieves, H. A., Bosmuler Züge, L. C., de Paula Scheer, A., Ribani, R. H., Morales, P., \& Sánchez-Mata, M. C. (2016). Physical properties and rheological behavior of pseudofruits of Hovenia dulcis Thunb. in different maturity stages. Journal of Texture Studies. http://dx.doi.org/10.1111/jtxs.12199.

Maieves, H. A., López-Froilán, R., Morales, P., Pérez-Rodríguez, M. L., Ribani, R. H., Cámara, M., et al. (2015b). Antioxidant phytochemicals of Hovenia dulcis Thunb. peduncles in different maturity stages. Journal of Functional Foods, 18, 1117-1124.

Maieves, H. A., Ribani, R. H., Morales, P., \& Sánchez-Mata, M. C. (2015a). Evolution of the nutritional composition of Hovenia dulcis Thunb. pseudofruit during the maturation process. Fruits, 70, 181-187.

Morales, P., Barros, L., Ramírez-Moreno, E., Santos-Buelga, C., \& Ferreira, I. C. F. R. (2015). Xoconostle fruit (Opuntia matudae Scheinvar cV. Rosa) by-products as potential functional ingredients. Food Chemistry, 185, 289-297.

NCCLS - National Committee For Clinical Laboratory Standards (1997). Method for Broth Dilution Antifungical Susceptibility Testing of Yeast; Approved Standard. Villanova, v. 17, p. 28. M27-A.

Nogala-Kalucka, M., Kupczyk, B., Polewski, K., Siger, A., \& Dwiecki, K. (2007). Influence of native antioxidants on the formation of fatty acid hydroperoxides in model systems. European Journal of Lipid Science and Technology, 109(10), $1028-1037$.

Ozawa, T., Lilley, T. H., \& Haslam, E. (1987). Polyphenol interactions: Astringency and the loss of astringency in ripening fruit. Phytochemistry, 26(11), 2937-2942.

Park, J. S., Kim, I. S., Rehman, S. U., Na, C. S., \& Yoo, H. H. (2015). HPLC determination of bioactive flavonoids in Hovenia dulcis fruit extracts. Journal of Chromatographic Science, bmv114.

Pinto, J. T., Oliveira, T. T. D., Alvarenga, L. F., Barbosa, A. S., Pizziolo, V. R., \& Costa, M. R. D. (2014). Pharmacological activity of the hydroalcoholic extract from Hovenia dulcis thunberg fruit and the flavonoid dihydromyricetin during hypercholesterolemia induced in rats. Brazilian Journal of Pharmaceutical Sciences, 50, 727-735.

Qiao, X., He, W. N., Xiang, C., Han, J., Wu, L. J., Guo, D. A., et al. (2011). Qualitative and quantitative analyses of flavonoids in spirodela polyrrhiza by high-performance liquid chromatography coupled with mass spectrometry. Phytochemical Analysis, 22, 475-483.

Rigatto, P. A., Pereira, J. C. D., Mattos, P. P., \& Schaitza, E. G. (2001). Características Físicas, Químicas e Anatômicas da Madeira de Hovenia dulcis. Comunicado Técnico - Embrapa Florestas - Colombo - PR.

Roowi, S., \& Crozier, A. (2011). Flavonoids in tropical citrus species. Journal of Agricultural and Food Chemistry, 59, 12217-12225.

WHO (2014). Antimicrobial resistance: global report on surveillance 2014, ISBN: 9789241564748 .

Yoo, S. M., Mun, S., \& Kim, J. H. (2006). Recovery and pre-purification of (+)dihydromyricetin from Hovenia dulcis. Process Biochemistry, 41, 567-570. 